\title{
Análise do impacto do ensino das competências interprofissionais através de diferentes estratégias educacionais em graduandos da área de saúde
}

\author{
Cyntia Pace Schmitz Corrêa, Oscarina da Silva Ezequiel, Giancarlo Lucchetti
}

\begin{abstract}
Resumo
INTRODUÇÃO: Em todo o mundo, gestores, educadores, formuladores de políticas e profissionais de saúde consideram que os sistemas de saúde têm se mostrado cada vez mais fragmentados, gerando dificuldades na solução dos problemas. Neste contexto, a Organização Mundial de Saúde (OMS) publicou em 2010 um Marco para Ações em Educação Interprofissional e Prática Colaborativa, na busca da valorização do trabalho colaborativo em saúde como o melhor caminho para promover o cuidado centrado no paciente e com qualidade máxima. De acordo com a definição da CAIPE - Centre for the Advancement of Interprofessional Education, a EIP "ocorre quando duas ou mais profissões aprendem com, para e sobre o outro para melhorar a prática colaborativa e qualidade dos cuidados". No Brasil, as Práticas Colaborativas Interprofissionais (PCI) tem sido uma preocupação do processo formador, buscando o fortalecimento dos princípios fundamentais do Sistema Único de Saúde (SUS). Além disso, diretrizes curriculares de vários cursos da saúde apontam para a necessidade de se aprender a trabalhar em equipe colaborativamente. A literatura que respalda os estudos sobre a EIP traz uma quantidade razoável de evidências sobre os impactos da eficácia e eficiência desta prática à curto prazo. Muitos destes estudos apontam para mudanças de atitudes em equipes e melhora nas capacidades cognitivas relacionadas com temas específicos, como por exemplo, manejo nos cuidados do paciente com demência e habilidade de ressuscitação. Apesar de observarmos uma quantidade razoável de estudos abordando a necessidade de implementação de estratégias de EIP, quase não se observa pesquisas mostrando como é trabalhada a aprendizagem desta temática com os alunos na graduação. Em particular na EIP, a utilização de metodologias de ensino tradicionais e/ou ativas, acrescidas de técnicas que trabalham a coletividade e a cooperação, pode influenciar diretamente na disposição futura dos profissionais para o trabalho interprofissional. OBJETIVO: Avaliar se diferentes metodologias educacionais utilizadas para ensinar as competências interprofissionais para alunos de graduações em saúde interferem na prontidão, na percepção e no reconhecimento da importância do da educação e do trabalho interprofissional, além de fortalecer ações de EIP nos cursos da área de saúde da UFJF. MÉTODOS: Estudo de intervenção educacional, quantitativo, prospectivo, sobre o impacto de diferentes metodologias educacionais no desenvolvimento das competências para o trabalho interprofissionais em estudantes dos cursos de Enfermagem, Fisioterapia, Medicina, Nutrição, e Psicologia da Universidade Federal de Juiz de Fora. Uma disciplina eletiva foi criada especialmente para este fim. Os temas abordados no conteúdo da disciplina são: importância do trabalho interprofissional e das competências interprofissionais; clarificação de papéis; cuidado centrado no paciente/família/comunidade; trabalho em equipe; liderança colaborativa; comunicação interprofissional e resolução de conflitos). Outros temas relacionados com prática clínica e gerenciamento de cuidados do paciente idoso são apresentados aos alunos para que possa servir de base para as atividades práticas e discussões em grupo. Neste primeiro semestre de oferecimento foi utilizada a ESTRATÉGIA TRADICIONAL de ensino, com foco no domínio cognitivo, através de palestras do conteúdo proposto e trabalhos individuais realizados pelos alunos. Nos semestres subseqüentes serão utilizadas outras estratégias de ensino. Para avaliação das estratégias, os alunos participantes preenchem, no início do período (Momento Pré-Intervenção), um questionário de avaliação demográfica, a RIPLS (Readiness for Interprofessional Learning Scale), o IEPS
\end{abstract}


ISSN 2179-6750

(Interdisciplinary Education Perception Scale) e o TSS (Team Skills Scale), objetivando mensurar atitudes, percepções e habilidades frente a interprofissionalidade, além de possíveis mudanças em seus comportamentos no cuidado e assistência ao paciente. No final do período (Momento PósIntervenção Imediato) os alunos preencherão novamente as escalas (RIPLS, IEPS e TSS) e responderão um questionário de feedback da disciplina, no intuito de ver a satisfação com a disciplina e o quanto cada aluno gostou do método aplicado. Seis meses após a conclusão da disciplina as escalas serão reaplicadas (Momento Pós-Intervenção Tardio),. As escalas IEPS e TSS foram traduzidas e validadas pela equipe de pesquisa do projeto e estão em fase final de análise e publicação. Todos os dados obtidos serão tabulados em um banco de dados do programa Excel for Windows e exportados para o programa estatístico SPSS 21 (SPSS Inc.), para que possa ser feito a análise. Primeiramente, será realizada a análise descritiva das principais variáveis. Depois, serão comparadas os momento pré-intervenção e pós intervenção imediata e tardia. Para isso, serão utilizados o ANOVA para medidas independentes (comparação entre os grupos) e ANOVA para medidas repetidas (comparação do mesmo grupo em três diferentes momentos, pré, pós e pós tardio). O teste post-hoc será determinado posteriormente. Adotar-se-á p $<0.05$ como significante e intervalo de confiança de $95 \%$. Para as questões abertas descritas no questionário de feedback final da disciplina, as respostas serão categorizadas de forma a levantar as fortalezas e fragilidades do processo educacional desenvolvido. RESULTADOS: Neste semestre (02/2017) a disciplina foi colocada em carga e estamos trabalhando com 23 alunos dos cursos de Fisioterapia, Medicina, Nutrição e Psicologia. A estratégia sorteada para este semestre foi a TRADICIONAL e conduzimos a disciplina como um Projeto Piloto para fortalecer conteúdos e mensurar estratégias para as próximas turmas. Salientamos que, em todas as aulas existe uma grande preocupação da equipe em conduzir a disciplina de maneira prazerosa e significativa e, em momento algum, estamos conduzindo o modelo dito "TRADICIONAL" de forma enfadonha e monótona. Observamos uma grande dificuldade na participação dos alunos dos cursos de Enfermagem (alunos se matricularam, mas não cursaram a disciplina) e Medicina. Estratégias foram desenvolvidas com os coordenadores desses cursos para facilitar a adesão no próximo semestre, como envolver a disciplina nas Ligas Acadêmicas de Geriatria e Saúde Comunitária. Para os alunos cursistas, o retorno está sendo muito positivo. Até o fechamento deste resumo, a disciplina ainda estava em carga, portanto, não havíamos aplicado as escalas pós intervenção. DISCUSSÃO: A implantação de disciplinas que trabalhem os temas da EIP nos cursos da saúde na UFJF é uma novidade e, como tal, temos enfrentado alguns problemas para despertar o interesse dos alunos. Acreditamos que, no próximo semestre, com o sucesso observado neste período e com as estratégias adotadas em parceria com os coordenadores dos cursos mais resistentes, conseguiremos desenvolver os conteúdos nas outras estratégias programadas.

Descritores: Educação Interprofissional, Estratégias Educacionais, Metodologias de Ensino, Ensino em Saúde Ensino em Graduações 